\title{
The Sustainability of our Common Future: An Inquiry into the Foundations of an Ideology
}

\author{
Pieter Tijmes and Reginald Luijf
}

ABSTRACT. This paper examines the modern philosophical background of the idea of sustainable development, especially as it bas been articulated by the World Commission on Environment and Development in the document entitled Our Common Future (1987). We argue that this document is not nearly as radical as is sometimes supposed, but in fact only extends the principles of the economics of scarcity into the realm of environmental ecology.

Just over a 100 years ago the British government dispatched to India an eminent chemical agricultural scientist, Dr John Augustus Voelcker, charged with the task of determining how to improve indigenous agriculture. Officials of the Department of Colonial Affairs were no doubt surprised by his report: "I do not share the opinions which have been expressed as to Indian agriculture being as a whole primitive and backward, but I believe that in many parts there is little or nothing that can be improved. . . I make bold to say that it is a much easier task to propose improvements in English agriculture than to make really valuable suggestions for that of India."

At the British department the prevailing view was that because of its inefficiency, traditional agriculture always had to contend with the scarcity of nature. But according to Voelcker, the situation in India was not what was expected. Instead, he discovered a society that was not properly interpreted in economic terms and he realized that scarcity, a fundamental presupposition of modern economics, did not have universal validity. His insight into the difference between agricultural production under traditional and under modern conditions led Voelcker to abandon his task.

Pieter Tijmes is a professor of social and political philosophy at the University of Twente, The Netherlands. His research focuses on the philosophy of technological culture, with recent publications on the thought of Hannah Arendt and Rene Girard. Reginald Luijf is a graduate student in philosopby at the University of Twente who currently resides in Switzerland. 
Scarcity is not a universal phenomenon, but has a history. It was the economic historian Karl Polanyi who first clearly drew attention to the fact that the conceptualization of scarcity is also the origin of a free market economy. ${ }^{2}$ Since Polanyi, a growing number of scholars have recognized that modern society is distinguished from all previous ones by the idea of scarcity. From this perspective all sorts of post-medieval ideas and arguments by political and social philosophers take on a new meaning. Even the modern attempt to develop underdeveloped countries and to radically change traditional cultures appears in a new light. Many international reports on poverty and environmental pollution in the so-called "Third World" reflect the same idea of development already rejected by Voelcker.

Our Common Future of the World Commission on Environment and Development is a typical example. ${ }^{3}$ This Report, which has become an influential document among people concerned about both the environment and the Third World, claims to advocate a change in modern "attitudes" and "values" with regard to economic growth and the environment. But in fact the Report fails to question typically modern assumptions and represents no more than a slight adjustment in what must be identified as a distinctively modern interpretation of the human condition.

\section{From Shared Shortages to Competitive Scarcities}

According to the respected Dutch economist Arnold Heertje, "Economic science begins with the assumption that human beings have indefinite needs that they want to satisfy. The means for satisfying these needs are called goods, and all goods are scarce. That is, the means to satisfy the needs are always limited." Such assumptions apply to contemporary society, but it is possible to doubt their application to a traditional society. As the historian of ideas Louis Dumont has argued in detail, classical modern economists such as John Locke, François Quesnay, Adam Smith, and Karl Marx share a view of human nature that would be inconceivable before the 18 th century. This is the view of the human being as borno economicus whose behavior is determined by scarcity. ${ }^{5}$

Ironically, only modern and affluent societies are convinced about the importance of scarcity as a determinant of social behavior, while traditional societies tend to rest on a different conviction. In traditional cultures, wishes and desires are not seen as endless or indefinite but as religiously and culturally constrained. Of course, traditional societies are used to shortages, but precisely because of a commitment to the constraint of desire such shortages are dealt with in ways quite different from those typical of modernity.

To state the issue dramatically, a shortage of sheep does not necessarily mean a scarcity of sheep. Sheep are scarce only when they become an issue of competition or rivalry. But in a traditional society all sorts of institutions - religious myths and rites, cultural interdictions, division of space - function to prevent or limit rivalries. One tries to avoid situations in which things become the objects of competitive desire. What we call 
economic competition is subordinated to the harmony of society. Neither economic laws nor maximizing self-interest, but traditional norms and institutions, are the primary influences on the nature and scale of production. Production is not for a market but for subsistence. As Marshall Sahlins argues in his somewhat ironically titled Stone Age Economics, there is a difference between production for use instead of economic gain. ${ }^{6}$ In the former, economic imperatives do not exist or exist only in attenuated form.

René Girard, the great contemporary interpreter of the mythological and literary narratives of the dialectic of desire and competition, has observed that "When men no longer live in harmony with one another, the sun still shines and the rain falls, to be sure, but the fields are less well tended, the

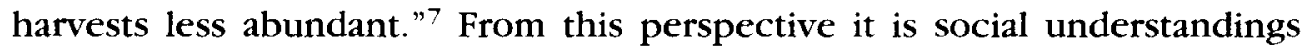
of the fundamental meaning of human existence that are the main determinant of the appearance of scarcity - a view that might be argued to be confirmed, for instance, by recent events in Somalia and Rwanda. Shortages of natural resources do not define scarcity; scarcity is the social construct of a particular web of human relationships. It is in this sense that Paul Dumouchel, following Girard, contends that scarcity is the organizing principle of modern society. In this sense scarcity entails "general abandonment of the obligations of solidarity which united the community. Scarcity is the deliberate abandonment of the religious interdictions that restricted human desires." 8

This is the climate within which bomo economicus originally appears and flourishes. It is a new realm in which people look out for and protect their own interests while paying little or no attention to the interests of a neighbor - except insofar as the satisfaction of a neighbor's interests can be of economic benefit to them. Thus we witness an "explosion" of economic growth arising from countless independent and isolated rivalries which, however, go hand in hand with the destruction of old institutions that once guaranteed community solidarities. Thus it is the abandonment of solidarity that creates scarcity.

A striking example of the establishment of the new order is related by the social historian Fernand Braudel. In the early modern period, towns sometimes were faced with the sudden appearance of large numbers of the poor. Beggars appeared in the field and streets of the town of Troyes in 1573 , starving, clothed in rags, and covered with fleas and vermin. The rich soon began to worry about the danger of "sedition" among the poor. The town council held a meeting in order to decide on a course of action. The decision was taken to chase the poor out of the city. To this end, citizens of the town baked a large amount of bread, then assembled the poor at one of the main gates of the city. Then, after being led outside the city and given a loaf of bread and a coin, the gates were closed, and the poor told to seek their refuge in God, to find their livelihood elsewhere, and not to return to Troyes before the new grain from the next harvest.

This process of abandonment of social solidarity begins first among the upper classes in the cities. Already in competition with the nobility, they 
became afflicted with a new sense of scarcity, while the lower classes of citizens continued to live under a regime of communal constraints and according to acknowledged obligations of solidarity. "Significantly," according to Braudel, "in Dijon the municipal authorities went so far as to forbid the town's citizens to take in the poor or to exercise private charity."

Another important contribution to the new order of scarcity is the "enclosure" of the medieval "commons" on the eve of the Industrial Revolution. The commons were an expression of the ties of solidarity, whereas the enclosure was part of a process of the rationalization of agricultural production. In the old division of the land, cultivation took place according to communal more than economic rules. Scarcity as an abandonment of social solidarity is always an ambivalent or two-edged sword. On the one hand, this abandonment makes possible rivalries that lead to the accumulation of unprecedented riches. On the other, the victims of the rivalries abandoned to their fate, pay the costs involved in the disappearance of the old world.

To justify this new situation it is typical of bomo economicus to conceive human beings as isolated individuals involved in a competitive rivalry for the oikos, now understood as the whole of productive resources to be found in society. Distinctive of the postmedieval philosophical tradition is the idea that scarcity under such conditions is the cause of violence. According to both Liberals and Marxists, human desires are focused on the same object because of a limitation of resources. In an interesting way, Girard and Dumouchel turn this idea around. It is rivalry that creates scarcity, not scarcity that creates rivalry. The discovery of scarcity in nature as the cause of social violence has, according to Dumouchel, made possible the articulation of modern economic principles as ethical and political ideals. The typically modern argument runs as follows; if the cause of violence is a shortage of goods, then economic competition and an accompanying explosion of economic growth are the only means to social stability. This economic ideology - in which economic development replaces religious restraint - is a revolutionary approach to social order, because it conceives one kind of social rivalry, namely economic rivalry, as the foundation for peace in all other aspects of society.

\section{Economic Scarcity Heightened by Environmental Deterioration}

In its emphasis on the need for economic development, the Report of the World Commission on Environment and Development presented in Our Common Future is only the late-20th century version of the distinctly modern ideology of scarcity. What is unique about the Report is the role it gives to scarcity created not just by social but as a result of technological activity, that is, environmental deterioration.

It is obvious, for instance, that many factors play a role in the problems of developing countries. And it seems to go without saying that political tensions and military conflicts are provoked by shortages of resources. But according to the World Commission these problems are uniquely intensified by environmental degradation. For example, the misery of political refugees 
from the Third World is attributed to something more fundamental than the simple absence of social solidarity. "The immediate cause of any mass movement of refugees may appear to be political upheaval and military violence. But the underlying causes often include the deterioration of the natural resource base and its capacity to support the population" (p. 291). Indeed, in its formulation of the new concept of "environmental [as opposed to political] refugee," and from its discussion of the desertification of agricultural lands to a thinning of stratospheric ozone, the whole tenor of the Report is that the ultimate danger to humanity is the "dangerously rapid consumption of finite resources" (p. 5).

According to the World Commission, "The deepening and widening environmental crisis presents a threat to national security - and even survival - that may be greater than well-armed, ill-disposed neighbors and unfriendly alliances" (pp. 6-7). And again: "The whole notion of security as traditionally understood - in terms of political and military threats to national sovereignty - must be expanded to include the growing impacts of environmental stress - locally, nationally, regionally, and globally" (p. 19). Natural scarcity, which was supposed to have disappeared from the developed world structured on either Thomas Hobbes' "Leviathan" or John Locke's "social contract" - both of which left the "civil" or economic sphere open to endless competition and economic advance - re-emerges as the "disrupted ecosystem."

Although economic growth, which postmedieval political philosophy presents as the solution to social violence, has given rise to a disrupted ecosystem, the problem is not so much substantial as accidental. "The failures that we need to correct arise both from poverty and from the short-sighted way in which we have often pursued prosperity" (p. 27). It was a mistake not to take nature into account and thus to over-exploit natural resources. In one sense, economic growth was short-sighted. But the announced reform is scarcely revolutionary. "We see the possibility for a new area of economic growth, one that must be based on policies that sustain and expand the environmental resource base. And we believe such growth to be absolutely essential to relieve the great poverty that is deepening in much of the developing world" (p. 1).

The World Commission in no way bids farewell to economic growth formulated on the basis of the concept of scarcity but simply reformulates the concept of growth as sustainable development. In this way it explicitly admits that the problem of economic growth lies only in its accidental or prior historical manifestations. In the liberal tradition, economic development continues to be defended as a necessary fight against scarcity indeed, as a fight that must be sustained.

When the World Commission began its work, descriptions of environmental calamities due to economic growth were abundant. These descriptions confronted the Commission with the same ambivalence created at the beginning of the Industrial Revolution, when rationalization and increased production went hand in hand with famine and the destruction of traditional cultures. "It is a terrible irony that as formal development reaches more 
deeply into rain forests, deserts, and other isolated environments, it tends to destroy the only cultures that have proved able to thrive in these environments" (p. 115). But this ambivalence is then concealed beneath the allegation that previous economic development failed to respect and protect traditional agricultural practices and methods, while sustainable growth and development will do so.

Yet there is good reason to assert that growth is always a two-edged sword. The process of economic growth institutionalizes scarcity because this process destroys the old institutions of solidarity in a community. Economic growth and progress are not to be separated from ambivalence. Growth creates at the same time economic wealth and environmental degradation because it can only appear within an order which is built on selfishness and rivalry. But although the Commission admits that growth and development are double-sided, Our Common Future in no way distances itself from them. It turns out that "the changes in attitudes, in social values and in aspirations" ( $p$. xiv) advocated by the Commission are not new values at all. They only point towards a more economical use of scarce resources, with no limitation put on needs and desires. "The concept of sustainable development does imply limits - not absolute limits but limitations imposed by the present state of technology and social organization on environmental resources and by the ability of the biosphere to absorb the effects of human activities. But technology and social organization can be both managed and improved to make way for a new era of economic growth" (p. 8).

Precisely for this reason the World Commission claims to understand the signs of the times. "Previously our main concerns centered on the effects of development on the environment. Today, we need to be equally concerned about the ways in which environmental degradation can dampen or reverse economic development" (p. 35). Ecology now becomes the way to more effective and sustainable economic growth, and as a result becomes itself subsumed within economics. According to this expanded economic logic, men and women in traditional cultures become resources which have to be developed for the sake of the struggle against scarcity. According to the Commission, "People are the ultimate resource. Improvements in education, health, and nutrition allow them to better use the resources they command, to stretch them further" (p. 95). By contrast, one might well argue that ecology must set aside the economic orientation if it does not want to bring about its own destruction.

In this Report, for instance, economic ecology or ecological economics now encompasses all cultural activities. Even the activity of a woman who cooks is reduced to the consumption of scarce resources: "The woman who cooks in an earthen pot over an open fire uses perhaps eight times more energy than an affluent neighbor with a gas stove and aluminum pans" ( $p$. 196). Objects of culture are only valued as ecological and economic goods. Within this view these cultural objects can then easily be substituted by more "efficient" objects. But the woman in a traditional culture is neither a genderless individual nor a femina oeconomica. Her needs are limited. The 
tools she uses are part of a common and sharable world, although one shot through with boundaries and numerous restraints. ${ }^{10}$ As long as ecology fails to recognize this aspect of tools, it promotes the destruction of traditional subsistence and those limits which have been so carefully drawn by culture - thereby initiating societies into unlimited economic growth.

\section{The Return of Malthus and Development through Education}

In modern economic theory, poverty is due to a combination between scarce nature and an absence of the economic spirit. Thomas Malthus, although more widely noted for his postulate of a contradiction between the growth curves in population and agricultural production, took the logic of scarcity one step further. For Malthus, poor-laws, or governmental attempts to alleviate poverty, "will always tend to aggravate the evil lof poverty] by diminishing general resources of the country." "Similarly, the Commission Report focuses attention on a phenomenon until then neglected: that poverty itself contributes to degradation of the environment. Like a Malthus Recidivus, the Commission argues that "Those who are poor and hungry will often destroy their immediate environment in order to survive: they will cut down forests; their livestock will overgraze grasslands; they will overuse marginal land; and in growing numbers they will crowd into congested cities" (p. 28). Poverty is not the result of economic growth and the transformation of social relationships that takes place in its wake, but poverty is the ultimate cause of degradation of the environment and the bad economic situation of the developing countries. This view so distorts the perception of the Commission that it contends "poverty is a major cause and effect of global environmental problems" (p. 3). It is poverty that causes degradation of the environment "and environmental degradation can undermine economic development"(p. 3). The Commission thus repeats the classical formula that economic growth has absolute priority, and that the poor themselves undermine scarce resources.

Political philosophy since the Middle Ages has explored all possible solutions to the problem of threatening scarcity. Especially Malthus who already realized that economic growth as well as birth control had to be preceded by a long process of "civilization" to familiarize "savages" with the imperatives of a modern society. He complained, for instance, that "To civilize and direct the industry of the various tribes of Tartars and Negroes would certainly be a work of considerable time and of variable and uncertain success." 12

In the 16th century beggars were given food before they were sent away. At the beginning of the 17th century other measures were taken: their heads were shaved. Later they were lashed. And by the end of the century the ultimate remedy was discovered: they were sent to school. Likewise, for the Commission, the response to a deficit of resources, especially in the Third World, should be "education to improve human potential to manage those 
resources" (p. 11). Schools are proposed as the means to "civilize and direct the industry" of those in the developing countries.

Less developed countries must themselves be developed so they can manage their resources efficiently. Modern education teaches that everything from water to information and knowledge - is a scarce, economic good. Moreover, insofar as "most people base their understanding of environmental processes and development on traditional beliefs or on information provided by a conventional education [they] remain ignorant about ways in which they could improve traditional production practices and better protect the natural resource base" (p. 113). In short, traditional knowledge must abandon the field to modern knowledge, which opens the door to sustainable development. Twenty years ago, the Dutch world-federalist B.V.A. Röling used a less veiled language. Traditional religious, moral, and social attitudes and opinions oppose economic progress and obstruct the doing of what is necessary. ${ }^{13}$

\section{Ithe Dream of a Universal Language and an End of Sustainability}

The dream to be able to speak all languages is different from the dream that all should speak one language. The latter dream is a relatively modern one. One realization of this dream involves extension of the economic world view to all fields of human culture and the destruction of any structures that resist economic activities and technical innovation. This dream began with John Locke. When everyone speaks the language of economic order, scarcity will be more easily overcome. Locke defended private property in the belief that cultivation of the land was not tied to communal restrictions. Voelcker, however, realized that such a regime of "speaking one language" would be disastrous for traditional cultures.

But the Commission advocates precisely this regime of a universal language. Its plea for "helping to define shared perceptions of long-term environmental issues and appropriate efforts" and the necessity of a "world community" (p. ix) is a sublime illustration of the fact that cultural differences are considered to stand in the way of economic solutions to those global problems with which we have been confronted by the rise of scarcity economics. The term "world community" suggests that problems can be best handled on a global level. But this level is just a world of markets, desires, indefinite needs and cultural uniformity - and one in which everything is scarce. It may be a world, but it is not a community. In exchanging particular traditional communities for a new international order, the Earth as "common heritage" is reduced to a "common resource."

Although the Commission exhibits some appreciation of traditional social orders, it also recognizes that its new international order is ultimately destructive of subsistence community. "Traditional social systems recognized some aspects of the interdependence and enforced community control over agricultural practices and traditional rights relating to water, forests, and lands. This enforcement of the 'common interest' did not necessarily 
impede growth and expansion though it may have limited the acceptance and diffusion of technical innovations" (p. 47). In other words, the Commission thinks that economic growth may to some extent be possible within a premodern society. But its ideals are a new and better order in which everyone understands everyone else and in which economic growth is complemented by "well-enforced laws and liability legislation [that controls] harmful side effects" (p. 47). This is "sustainable development." What is clear is that for this to happen, traditional common interest ultimately has to give way to common interest of the international economic community. For example, although "the traditional rights of subsistence farmers. . and communal rights in particular must be respected [when] traditional practices threaten the resource base, their rights may have to be curtailed" (p. 142).

Within this new international community, technical innovation is not only possible but necessary. "First, the capacity for technical innovation needs to be greatly enhanced in developing countries so that they can respond more effectively to the challenges of sustainable development" (p. 60). The assumption underlying the Report is that "coping with often inadequate technology and few economic incentives, many [farmers] are pushed onto marginal land: too dry, too steep, lacking in nutrients" (p. 12). What the Commission fails to consider is that perhaps neither natural scarcity nor lack of technical knowledge but simply a surplus of economic incentives and the disappearance of a culture of shared community are the sources of such phenomena.

None of the problems which today threaten life on our planet have been created by traditional cultures. The permanent hunger and misery in the Third World are a consequence of the destruction of its old structures. This destruction takes place because people want to fight scarcity by means of an efficient economic organization. Qualifying the terms "growth" and "development" as sustainable is simply a contemporary attempt to hide the ambivalence of economic growth and scarcity. Thus the thought of the Commission remains circumscribed by the classical modern economic paradigm. The development of economic growth can only follow destruction of those traditional institutions that limit desires and are responsible for everyone sharing whatever they have. Violence in the economic order is the result of its exceptional efficiency of organization and not of its bad functioning. On rational arguments one should question the basic thinking of Liberal and Marxist traditions, both of which have focused their hopes exclusively on the development of productive forces in order to suppress scarcity. The Commission dreams of a future that will finally realize economic growth and harmony among people. But this is, and will remain, a dream. ${ }^{1+4}$

\section{Notes}

1. Voelcker is quoted from B. Dogra, "Traditional Agriculture in India: High Yields and No Waste," Ecologist, Vol. 13, Nos 2-3 (1983), p. 84.

2. See, e.g., K. Polanyi, The Great Transformation (New York: Rinehart, 1944).

3. World Commission on Environment and Development, Our Common Future (New York: Oxford 
University Press, 1987). The Commission was chaired by G. H. Brundtland, and thus also known as the Brundtland Report. (All page references in parentheses in the text are to this volume.)

4. A. Heertje, Scbaarste en Welvaart (Amsterdam: Naarden, 1983), p. 84.

5. L. Dumont, From Mandeville to Marx: The Genesis and Triumph of Economic Ideology (Chicago: University of Chicago Press, 1977).

6. M. Sahlins, Stone Age Economics (Chicago: Aldine, 1972).

7. R. Girard, Violence and the Sacred, trans. Patrick Gregory (Baltimore: Johns Hopkins University Press, 1977), p. 8.

8. P. Dumouchel, "L'ambivalence de rareté," in Jean-Pierre Dupuy and Paul Dumouchel, L'Enfer des choses: René Girard et la logique de l'économie (Paris: Seuil, 1979), p. 179.

9. F. Braudel, Civilization and Capitalism, 15th-18th Century, Vol. 1: The Structures of Everyday Life: The Limits of the Possible, trans. and rev. S. Reynolds (New York: Harper \& Row, 1981), p. 76.

10. See, e.g., I. Illich, Gender (New York: Pantheon, 1982), especially pp. 125-130.

11. T.R. Malthus, An Essay on the Principle of Population (first published, 1798; 7th edn, 1820), Book IV, chap. 8, last paragraph.

12. T.R. Malthus, Essay on Population, Book I, chap. I, tenth paragraph from the end.

13. B.V.A. Röling, "Poverty and Peace," in World Association of World Federalists, Youth and Student Division, World Peace through World Economy (Assen: Van Gorcum, 1968).

11. This article incorporates some suggestions from J. Tatum and $C$. Mitcham. The final English version was edited by C. Mitcham. 